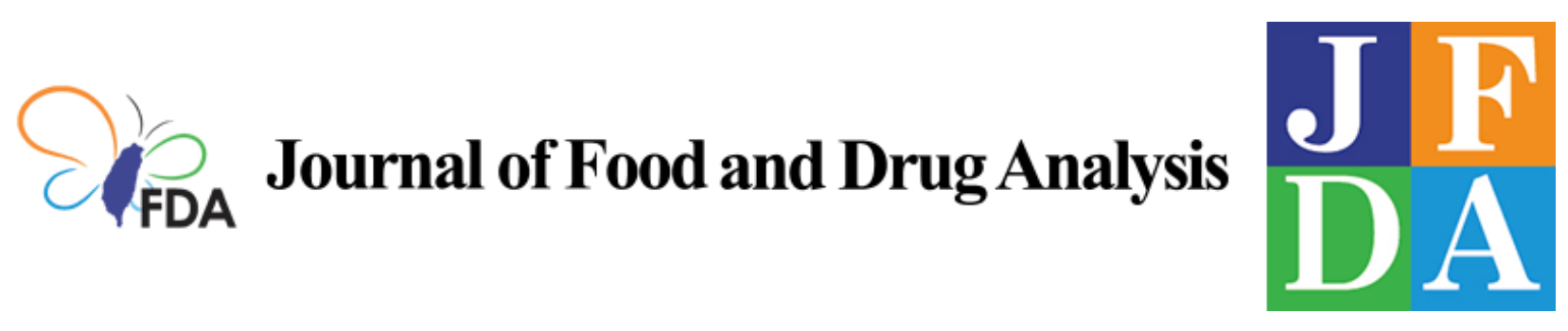

Volume 29 | Issue 1

Article 6

2021

\title{
Three-Way Analysis-Based pH-UV-Vis Spectroscopy for Quantifying Allura Red in An Energy Drink and Determining Colorant's pKa
}

Follow this and additional works at: https://www.jfda-online.com/journal

Part of the Analytical Chemistry Commons, Data Science Commons, and the Food Chemistry

Commons

(c) (i) (9)

This work is licensed under a Creative Commons Attribution-Noncommercial-No Derivative Works 4.0 License.

\section{Recommended Citation}

Dinç, Erdal Prof.; Ünal, Nazangül; and Ertekin, Zehra Ceren (2021) "Three-Way Analysis-Based pH-UV-Vis Spectroscopy for Quantifying Allura Red in An Energy Drink and Determining Colorant's pKa," Journal of Food and Drug Analysis: Vol. 29 : Iss. 1 , Article 6.

Available at: https://doi.org/10.38212/2224-6614.1275

This Original Article is brought to you for free and open access by Journal of Food and Drug Analysis. It has been accepted for inclusion in Journal of Food and Drug Analysis by an authorized editor of Journal of Food and Drug Analysis. 


\section{Three-Way Analysis-Based pH-UV-Vis Spectroscopy for Quantifying Allura Red in An Energy Drink and Determining Colorant's pKa}

\section{Cover Page Footnote}

In this study, analytical experiments and procedures were performed at the Chemometrics Laboratory of Faculty of Pharmacy, which was founded with the financial support of scientific research project number 10A3336001 of Ankara University. Authors also acknowledge the financial support from Ankara University through project 16L0237004. 


\title{
Three-way analysis-based $\mathrm{pH}-\mathrm{UV}-\mathrm{Vis}$ spectroscopy for quantifying allura red in an energy drink and determining colorant's pKa
}

\author{
Erdal Dinç*, Nazangül Ünal, Zehra Ceren Ertekin \\ Ankara University, Faculty of Pharmacy, Department of Analytical Chemistry, 06560, Yenimahalle, Ankara, Turkey
}

\begin{abstract}
Three-way analysis-based pH-UV-Vis spectroscopy was proposed for quantifying allura red in an energy drink product without the need for chromatographic analysis, and determining the colorant's pKa without using any titration technique. In this study, UV-Vis spectroscopic data matrices were obtained from absorbance measurements at five different $\mathrm{pH}$ levels from $\mathrm{pH} 8$ to $\mathrm{pH} 12$ and arranged as a three-way array (wavelength $\mathrm{x}$ sample $\mathrm{x} \mathrm{pH}$ ). In the three-way analysis procedure, parallel factor analysis (PARAFAC) was implemented to decompose the three-way array into a set of trilinear components. Each set of three components relates to spectral, $\mathrm{pH}$ and relative concentration profiles of allura red and sample matrix in the energy drink. First, UV-Vis spectra of the colorant's acid-base pair and sample's matrix were characterized by using the estimated spectral profile. Then, from the $\mathrm{pH}$ profile the pKa value was found to be 11.28 for the related colorant. Finally, allura red in energy drink samples was determined using the estimated concentration curve in the relative concentration profile. In the quantitation procedure, the working concentration range was $0.8-19.2 \mu \mathrm{g} / \mathrm{mL}$. PARAFAC approach was tested in terms of selectivity, precision, and accuracy of the method. Added recovery results obtained by applying the proposed method to spiked samples were between $101.5 \%$ and $103.5 \%$. In the application of the method to the analysis of real samples, successful results were reported. For a comparison, an ultra-performance liquid chromatographic method was developed for the quantitation of the colorant. Compared to the chromatographic method, we observed that PARAFAC model was simple and less expensive without requiring separation.
\end{abstract}

Keywords: Allura red AC dye, Energy drinks, pKa estimation, Quantitation, Three-way analysis

\section{Introduction}

$\mathrm{T}$ he analysis of various food products is usually accomplished by hyphenated chromatographic methods, such as ultra-performance liquid chromatography with photodiode array detector and mass spectrometry detector (UPLCPDA and UPLC-MS), which are designed to eliminate matrix effects. However, these techniques suffer from major disadvantages, such as being high-cost, time consuming, and need for well-trained workforce [1, 2]. In contrast, UV-Vis spectroscopy provides low-cost and simple analysis but it suffers from poor selectivity and interference from food matrix [3]. The use of three-way analysis methods for UV-Vis spectroscopic data can overcome the interference problem while maintaining the advantages of spectroscopy. [4, 5]. Moreover, three-way analysis-based spectroscopy may be used to reveal multiple characteristics of the analyte. For example, both the quantity and the pKa of an analyte can be simultaneously determined by three-way analysis of $\mathrm{pH}-\mathrm{UV}-\mathrm{Vis}$ absorbance data. In previous works, a three-way analysis method was applied to $\mathrm{pH}$-absorbance dataset for the simultaneous determination of the active pharmaceutical ingredients in syrup formulations

Received 9 July 2020; revised 17 August 2020; accepted 15 September 2020.

Available online 15 March 2021

* Corresponding author: Department of Analytical Chemistry, Faculty of Pharmacy, Ankara University, 06560, Yenimahalle, Ankara, Turkey. Fax: +90312 2131081.

E-mail address: dinc@ankara.edu.tr (E. Dinç). 
and their pKa value in spite of the matrix effects $[6,7]$. Various three-way analysis tools [8-13] have been used to solve complex problems in different fields of analytical chemistry [14-24]. However, three-way analysis methods have not been used for determining an analyte and its $\mathrm{pKa}$ value in food samples in literature. In this regard, we concluded that PARAFAC (parallel factor analysis) decomposition of spectroscopic data would provide a novel perspective for mathematical elution of analyte and interferents in food samples.

In food industry, several additives are used to increase the flavor, appearance and shelf life of products. Most of the food additives have weak acidic or basic character. The physicochemical phenomena in human body, such as absorption, permeability and distribution depend on the $\mathrm{pH}$ value of the biological media and the substance's acid-base dissociation constant [25]. Moreover, the acidity constant is very important to reveal physicochemical behaviors of additives in food products. Hence, the pKa value of any food additive is an important parameter for the production of food products $[25,26]$.

Allura red AC, which is a synthetic food colorant with the E number E129, is obtained from coal tar and petroleum products. Synthetic colorants are divided into five classes which are named as azo, triarylmethane, chinophthalon, indigo, and xanthenes. Allura red is a member of azo dyes' group. Allura red, which is named as disodium 6-hydroxy5-(2 methoxy-5-methyl sulphophenylazo)-2-naphthalenesulphonate, contains two sulpho groups, one phenolic group $(-\mathrm{OH})$ and one azo group $(-\mathrm{N}=\mathrm{N}-)$. The molecular formula of allura red was given in Fig. 1. Allura red is widely used in food and

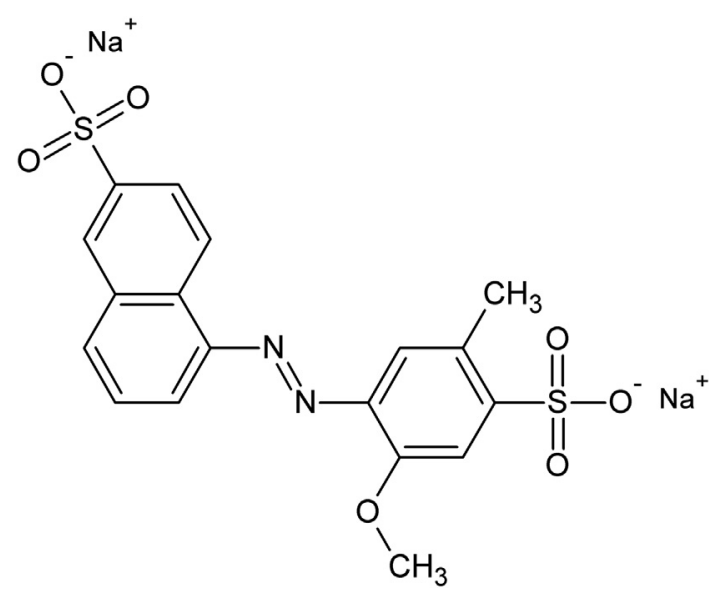

Fig. 1. Chemical structure of allura red AC (E129). pharmaceutical preparations as a coloring agent. Azo dyes have significant adverse effects on human health. For instance, consumption of allura red may cause asthma, DNA damage, allergic reactions and increased hyperactivity in children. Some countries have banned the use of allura red while the other countries have restricted it [27-34]. For this reason, the analysis of allura red is an important task in term of analytical chemistry and food industry.

Some papers including high-performance liquid chromatography [28-31], spectrophotometry [32, 3537], and capillary electrophoresis [38-40] were reported for the quantitative analysis of allura red in commercial energy drink samples. Several methods including potentiometric, spectrophotometric and electrophoretic techniques have been used for determining acidity constant of colorants in the literature [41-45]. In these studies, $\mathrm{pKa}$ determination required the use of conventional titration procedure or an extra software.

Literature survey has revealed that this is the first study to analyze allura red in energy drinks by three-way analysis of $\mathrm{pH}-\mathrm{UV}$-Vis-absorbance data. Moreover, this study is the first one in the literature to predict the quantity and pKa of allura red, simultaneously.

The focus of this study was the quantitation of allura red and its pKa determination by applying PARAFAC to the same $\mathrm{pH}-\mathrm{UV}-\mathrm{V}$ is spectroscopic dataset. The amount of allura red in energy drink was analyzed from the second mode (concentration profile) and $\mathrm{pKa}$ value of allura red was determined from the third mode ( $\mathrm{pH}$ profile) using the PARAFAC decomposition of spectral dataset. In this application, the quantitative analysis and $\mathrm{pKa}$ prediction was based on the mathematical extraction of individual spectral bands of allura red from the sample's spectral bands in food sample. The proposed method was validated in terms of accuracy, precision, and specificity for the quantitative analysis of the colorant's content by independent validation samples. Then, PARAFAC analysis was successfully applied to pH-UV-Vis-absorbance measurement data for the quantification of allura red and the determination of its $\mathrm{pKa}$ value.

In this investigation, a new UPLC method was developed as a reference method for the quantitative determination of allura red in energy drink sample. The determination results of allura red in energy drink provided from the PARAFAC application were statistically compared to those obtained by the UPLC method. The assay results provided by UPLC method were also compared to those obtained by classical UV-spectroscopic method. 
We concluded that, three-way analysis methods based on the resolution of $\mathrm{pH}-\mathrm{UV}-\mathrm{Vis}$ spectroscopic dataset were new and useful methodological approaches over more laborious and expensive methods for the analysis of food products and the pKa determination.

\section{Materials and methods}

\subsection{Apparatus and software}

Absorbance spectra (Shimadzu UV-2550 with UVPC software, Shimadzu, Japan) were recorded and transferred to a spreadsheet (Microsoft Excel Software, Microsoft, USA) prior to processing by the N-way Toolbox [46] in Matlab (Mathworks Inc., USA). Regression, quantification and figure plots were performed using an in-house algorithm written in Matlab platform. Chromatographic analyses were performed using a Waters Acquity $\mathrm{H}-$ Class System (Waters, USA) equipped with a quaternary solvent manager, a sample manager, and a photodiode array (PDA) detector. Empower2 software (Waters, USA) was used to record UPLC data.

\subsection{Chemicals and reagents}

Allura Red AC was supplied by Sigma-Aldrich, USA. Reagent grade $\mathrm{CH}_{3} \mathrm{COOH}, \mathrm{H}_{3} \mathrm{PO}_{4}$, triethylamine and gradient grade acetonitrile were purchased from Sigma Aldrich, USA. $\mathrm{NaOH}$ and $\mathrm{H}_{3} \mathrm{BO}_{3}$ produced by Riedel-de-Haën, Germany were used. All solutions, which were used for spectrophotometric and chromatographic analysis, were prepared by ultrapure water, obtained by Milli-Q Gradient A10 Millipore Purification System (Merck Millipore, USA). Commercial energy drink sample (Burn Energy Drink) was produced by the Coca Cola Company and obtained from a local market in Ankara, Turkey. The energy drink sample was stored at room temperature.

\subsection{Preparation of calibration and sample solutions}

Britton Robinson (BR) buffer solutions at five different $\mathrm{pH}$ levels $(\mathrm{pH} 8-\mathrm{pH} 12, \Delta \mathrm{pH}=1)$ were used for all spectrophotometric analysis. Buffer solutions were prepared by mixing fixed amounts of $\mathrm{CH}_{3} \mathrm{COOH}(0.04 \mathrm{M}), \mathrm{H}_{3} \mathrm{BO}_{3}(0.04 \mathrm{M})$ and $\mathrm{H}_{3} \mathrm{PO}_{4}$ $(0.04 \mathrm{M})$. The $\mathrm{pH}$ values of buffers were adjusted by $0.1 \mathrm{M} \mathrm{NaOH}$ (SevenCompact S220-Basic, Mettler Toledo, USA).
$10 \mathrm{mg}$ of allura red standard was weighed and dissolved in $100 \mathrm{~mL}$ buffer solution. The stock solution for each $\mathrm{pH}$ was prepared individually and freshly. All standard solutions were prepared from these stock solutions.

The calibration set was prepared in the range of $0.8-19.2 \mu \mathrm{g} / \mathrm{mL}$ by using the stock solution. In a similar manner, independent test samples (in the range of $0.8-14.4 \mu \mathrm{g} / \mathrm{mL}$ ) were obtained from the stock solution of allura red. The inter-day and intraday samples in three levels $(3.2,8.0$ and $12.8 \mu \mathrm{g} / \mathrm{mL})$ were prepared to get method validity. The standard addition samples were prepared by the addition of allura red's standard solution $(0,3.2,8.0$ and $11.2 \mu \mathrm{g} /$ $\mathrm{mL}$ ) to $0.8 \mathrm{~mL}$ of commercial energy drink. This procedure was repeated at each $\mathrm{pH}$ level for the preparation of calibration, validation and unknown sample sets.

\subsection{Chromatographic analysis}

The chromatographic separation was successfully performed on a Waters $\mathrm{BEH} \mathrm{C}_{18}$ analytical column (100 $\mathrm{mm} \times 2.1$ i.d., $1.7 \mu \mathrm{m})$ (Waters, USA) by using a mobile phase system containing a mixture of acetonitrile and $0.1 \mathrm{M} \mathrm{CH}_{3} \mathrm{COOH}$ solution containing $0.2 \%$ triethylamine $(18: 82, v / v)$ with $0.2 \mathrm{~mL} / \mathrm{min}$ flow rate. The stock solution of allura red was prepared by dissolving $10 \mathrm{mg}$ of allura red powder in $100 \mathrm{~mL}$ ultrapure water. Then, the stock solution was filtered with a cellulose nitrate filter with a pore size of $0.2 \mu \mathrm{m}$. All standard solutions were prepared from this filtered stock solution. As in UV-Vis spectrophotometry, the calibration curve of allura red in the range of $0.8-19.2 \mu \mathrm{g} / \mathrm{mL}$ was used for the chromatographic analysis of the related colorant. Chromatographic detection of samples was performed at the maximum wavelength $(240.0 \mathrm{~nm})$.

\subsection{Preparation of energy drink samples}

The energy drink samples were degassed for 20 minutes. For the analysis, $0.8 \mathrm{~mL}$ of this solution containing allura red was transferred into a $10 \mathrm{~mL}$ calibrated flask and the volume was completed with the buffer solution. The same procedure was repeated ten times for each $\mathrm{pH}$ media.

For chromatographic studies, the commercial energy drink sample was sonicated and filtered with cellulose nitrate filter with a pore size $0.2 \mu \mathrm{m}$. Then $0.8 \mathrm{~mL}$ of commercial energy drink was transferred to $10 \mathrm{~mL}$ volumetric flask and the volume was completed using ultrapure water. 


\section{Results and discussion}

Generally, the quantitative analysis of analytes in food products has been carried out by chromatographic methods, such as UPLC. In some cases, these chromatographic approaches may not provide desirable analysis results due to co-elution of active compounds, poor resolution, similar behavior of active compounds, and interference of sample's matrix on the analysis. Thus, a simple and efficient analytical method is necessary. With this aim, three-way analysis of $\mathrm{pH}-\mathrm{UV}-\mathrm{Vis}$-absorbance dataset may be preferred because it is rapid, low cost and do not require preliminary separation procedures. In this respect, PARAFAC is one of the most popular and widely used techniques for the applications that require fast analysis of a large number of food samples to get safe and quality products.

The spectral characterization, pKa determination, and quantitation of allura red in the presence of interferences were performed with the estimated profiles extracted from the $\mathrm{pH}-\mathrm{UV}-\mathrm{Vis}$-absorbance data array using PARAFAC modeling that did not require any separation step. The details about the PARAFAC application to pKa analysis and quantitative determination of allura red in commercial energy drink were explained below.

\subsection{PARAFAC method}

The first step in the application of PARAFAC model to $\mathrm{pH}$-spectral datasets was to find an optimal $\mathrm{pH}$ range that exhibits variation in spectral bands. In addition, in order to be able to determine the $\mathrm{pKa}$ value, the chosen $\mathrm{pH}$ range should include the $\mathrm{pKa}$ value of the related analyte. For these aims, the UV-Vis absorption spectra of allura red and commercial energy drink were recorded in the wavelength range of $207-620 \mathrm{~nm}$ (every $0.2 \mathrm{~nm}$ ) at different $\mathrm{pH}$ media. From the recorded spectra, the $\mathrm{pH}$ range from $\mathrm{pH} 8.0$ to $\mathrm{pH} 12.0$ was found to be the optimal one for the PARAFAC implementation. As it can be seen from Fig. $2 a$, the standard allura red gave different spectral bands at the selected $\mathrm{pH}$ range. In a similar manner, the change in the spectral bands of the energy drink product containing allura red at the same selected $\mathrm{pH}$ range was observed (see Fig. 2b).

Then, the UV-Vis spectra of calibration, validation and unknown samples for each $\mathrm{pH}$ were recorded between 207 and $620 \mathrm{~nm}$ (every $0.2 \mathrm{~nm}$ ). From the recorded spectra of the samples in the specified wavelength range, for mathematical treatments, the absorbance data matrix of size $1033 \times 52$ was
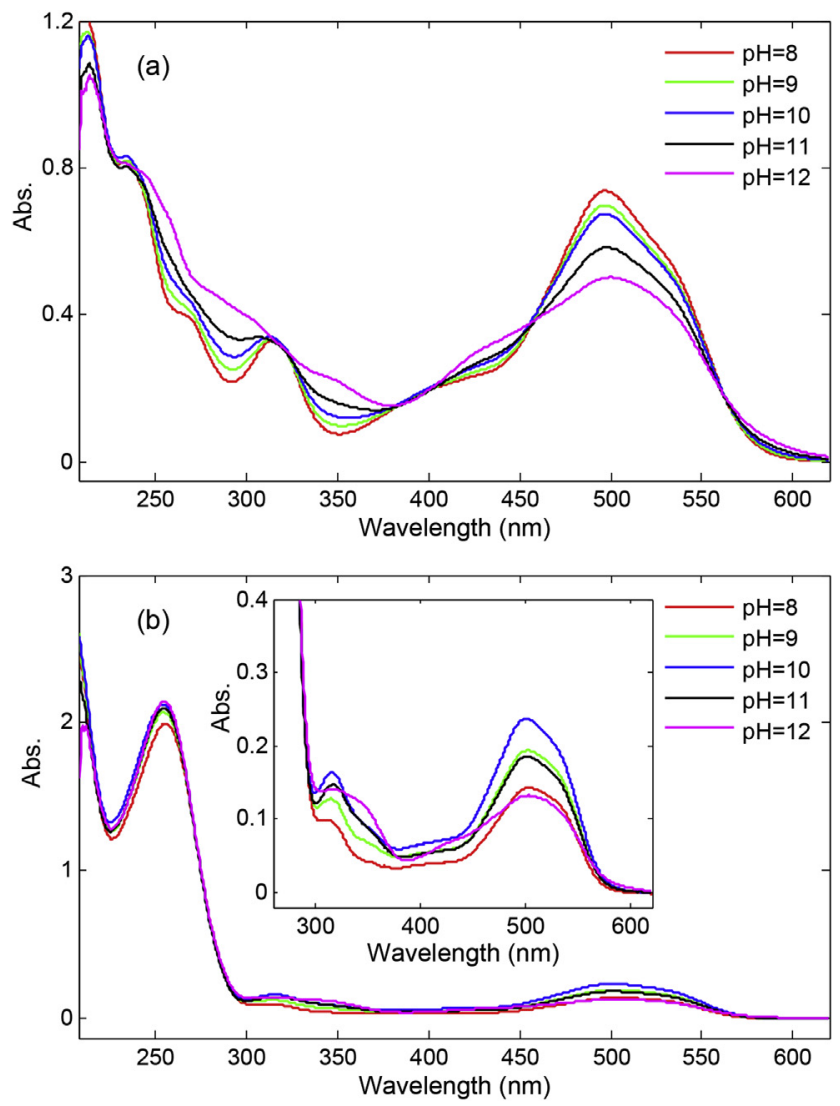

Fig. 2. UV/VIS spectra of a) allura red and b) real sample containing allura red at five different $\mathrm{pH}$ levels.

collected by reducing the size of the data with the interval of 2 for each sample and for each $\mathrm{pH}$ value.

A framework of spectral records and data measurements to obtain a three-way array of $\mathrm{pH}$ absorbance datasets was illustrated in Fig. $3 a-c$. For the implementation of the PARAFAC algorithm, the spectra of 52 samples (consisting of 6 calibration samples, 6 test samples, 12 standard addition samples, 9 inter-day samples, 9 intra-day samples and 10 unknown samples) at $\mathrm{pH} 8$ was obtained as an output in the form of UV-Vis-absorbance data matrix as shown in Fig. 3a. A similar procedure was repeated for each $\mathrm{pH}$ from $\mathrm{pH} 8$ to $\mathrm{pH} 12$. Thus, the $\mathrm{pH}-\mathrm{UV}-\mathrm{Vis}-\mathrm{absorbance}$ data matrix of size $1033 \times$ 52 were created for each $\mathrm{pH}$ value as displayed in Fig. $3 \mathrm{~b}$. In the next step, each matrix of UV-Visabsorbance data was added to a three-way array. Since the number of $\mathrm{pH}$ media was 5 , we obtained a three-way array with dimensions $1033 \times 52 \times 5$ (wavelength $\mathrm{x}$ sample $\mathrm{x} \mathrm{pH}$ ) as explained and given in Fig. 3c.

In the implementation of three-way analysis, the PARAFAC model was used for the decomposition of the three-way array ( $\mathrm{pH}-\mathrm{UV}-\mathrm{Vis}$ spectroscopic array in this study), $\underline{\mathbf{X}}$, illustrated in Fig. $3 \mathrm{c}$, into trilinear 
(a)

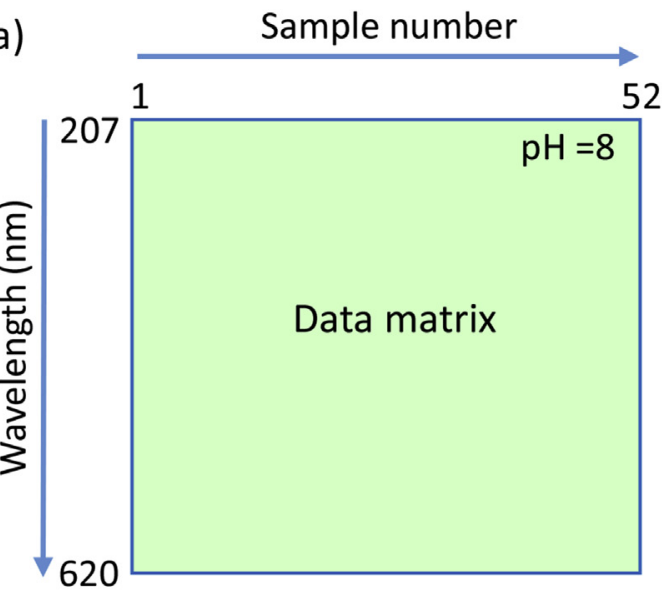

(b)

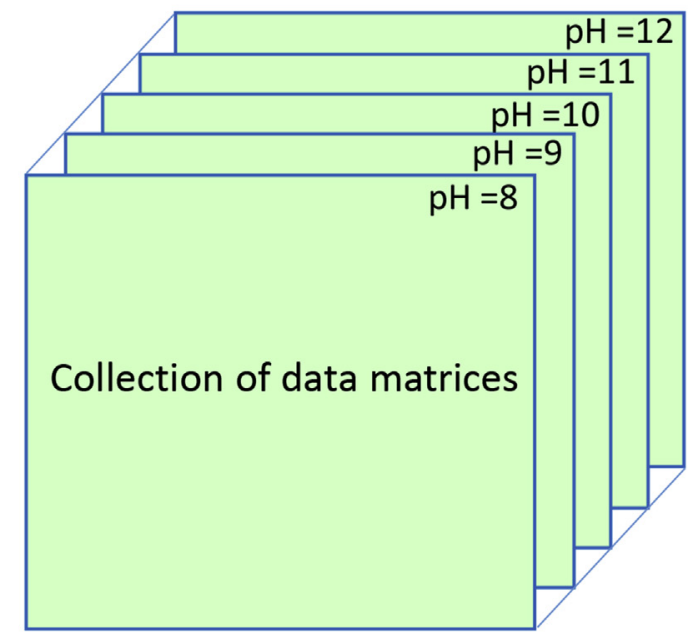

(c)

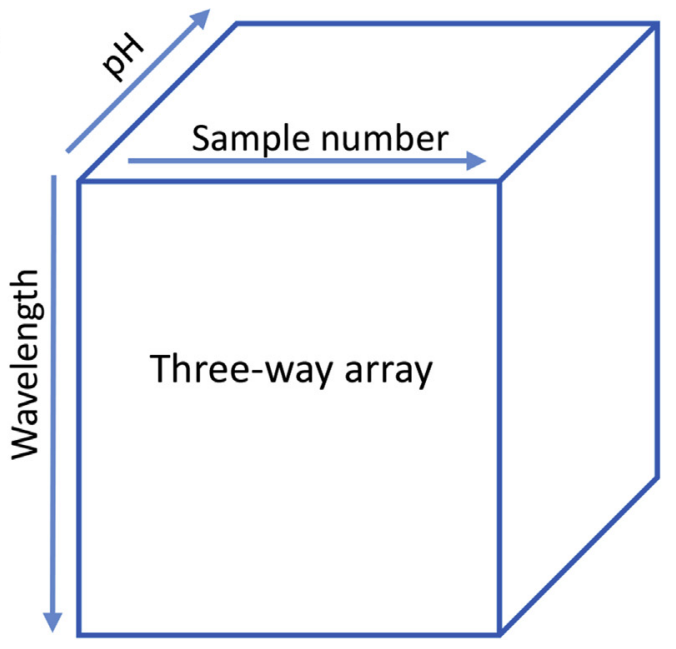

Fig. 3. Representative illustration of going from a matrix to a three-way array for UV-VIS spectra of samples at different $p H$ media $(p H 8, p H 9$, $p H$ 10, pH 11 and $p H$ 12). Here we showed a) data matrix with dimensions $1033 \times 52$ (wavelength $x$ sample), b) collection of data matrices and c) three-way array.

components (or loadings). The PARAFAC decomposition model for an element $X_{i j k}$ of a three-way array $\underline{\mathbf{X}}$ can be given by the following mathematical equation:
$X_{i j k}=\sum_{n=1}^{N} a_{i n} b_{j n} c_{k n}+E_{i j k}$

where $\mathrm{N}$ is the number of components in the fitting model, $E_{i j k}$ is an element of residual error of array $\mathrm{E}$. $a_{i n}, b_{j n}$ and $c_{k n}$ are an element of the column vector of $a_{i n}, b_{j n}$ and $c_{k n}$, corresponding to spectral, $\mathrm{pH}$ and relative concentration profiles for each $\mathrm{N}$ components, respectively.

In the deconvolution of three-way data array, different PARAFAC approaches based on the use of different component numbers with and without constraints were investigated $[47,48]$. The validation of the PARAFAC model has a very important role to get acceptable analysis results. For this purpose, core consistency diagnostic (CORCONDIA) [49] is a key parameter for estimating the appropriateness of the PARAFAC model for the explanation of fitting data. In the PARAFAC modeling, the number of components was three and non-negativity constraints were used in all of three modes. In the three-component PARAFAC modeling with nonnegativity constraints, the values of CORCONDIA and explained variation were reported as $98.51 \%$ and $99.60 \%$ to obtain the correct profiles for spectral, $\mathrm{pH}$ and sample modes. In the PARAFAC deconvolution procedure of three-dimensional data, the estimated profiles for spectral, $\mathrm{pH}$ and sample loadings were displayed in Fig. $4 a-f$.

From Fig. $4 a-c$, the individual contributions of components can be seen for the acid-base species of allura red and the matrix of the sample. To interpret carefully the PARAFAC results, the matrix's signals were removed from the estimated profiles showing spectral, $\mathrm{pH}$ and sample modes (See Fig. $4 \mathrm{~d}-\mathrm{f}$ ). In Fig. $4 d$, the spectral characterization of allura red was given as resolved spectral profile of colorant's acid-base species with the original UV-Vis spectrum of pure allura red (black dotted line). As can be seen in this figure, a good coincidence between the estimated spectrum (red line) and the original spectrum (black dotted line) of the analyzed colorant was reported. In order to avoid complexity, Fig. 4e showing the acid (red line) and base (blue line) forms in the resolved $\mathrm{pH}$ profile was obtained with the elimination of sample matrix (black dotted line) from Fig. $4 \mathrm{~b}$, presenting the $\mathrm{pH}$ profile obtained from spectral PARAFAC implementation. $p K a$ value of allura red was estimated by using the $\mathrm{pH}$ profile of acid-base pair showing different behaviors with the change in different media (See Fig. $4 \mathrm{~b}$ and $4 \mathrm{e}$ ). As seen in Fig. $4 b$, the behavior of the sample matrix, shown with the black line, was constant in the $\mathrm{pH}$ profile. The relative concentration levels of allura red's acid-base components were extracted 

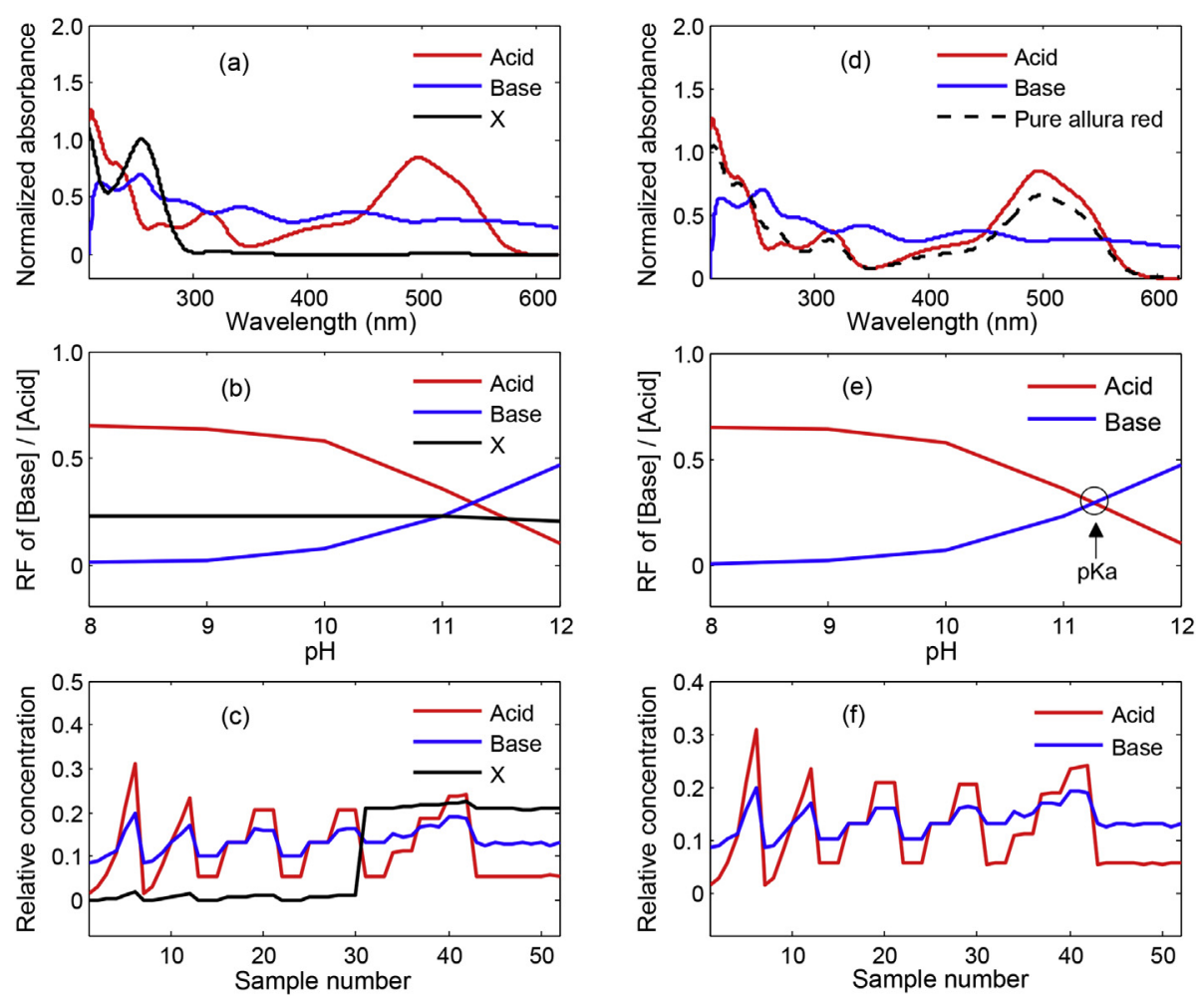

Fig. 4. Acid-base forms of allura red with $(a-c)$ and without $(d-f)$ the interference. (RF: relative fraction of acid-base species of allura red on the dissociation equilibrium).

from the $\mathrm{pH}$ profile containing the signals of acidbase forms and sample matrix, indicated in Fig. 4c, and then they were presented in Fig. 4f. The concentration profile of acid and base components of allura red, obtained from the sample mode using PARAFAC model, was used for the determination of the relative amount of the colorant in all samples containing calibration, validation and unknown samples in the presence of the interferences of the sample matrix.

\subsection{Validation of PARAFAC method}

From the perspective of analytical chemistry, validation is a requirement for the confirmation of a new method that will be used for quality control of samples. In our research article, the validation procedure and related details for the PARAFAC analysis were described below.

The calibration curve was calculated from the independent and dependent variables. The statistical results for the regression analysis and related parameters were summarized in Table 1 . As seen in this table, it was observed that LOD (limit of detection) and LOQ (limit of quantitation) were 0.20 $\mu \mathrm{g} / \mathrm{mL}$ and $0.66 \mu \mathrm{g} / \mathrm{mL}$, respectively.
In the method validation procedure test sample set was prepared and the PARAFAC model was applied to determine the content of allura red in independent test samples. The obtained results were illustrated in Table 2 to show the ability of the PARAFAC approach for the quantification of the colorant in samples of the test set. This experiment

Table 1. Statistical results of least square regression analysis and its related parameters.

\begin{tabular}{llll}
\hline Parameter & $\begin{array}{l}\text { PARAFAC } \\
\text { model }\end{array}$ & $\begin{array}{l}\text { Classical UV-VIS } \\
\text { spectroscopy }\end{array}$ & Classical UPLC \\
\hline $\mathrm{m}$ & $1.60 \times 10^{-2}$ & $5.35 \times 10^{-2}$ & $2.98 \times 10^{-1}$ \\
$\mathrm{n}$ & $3.62 \times 10^{-3}$ & $1.04 \times 10^{-2}$ & $4.68 \times 10^{-2}$ \\
$\mathrm{r}$ & 0.9999 & 0.9997 & 0.9998 \\
$\mathrm{SE}(\mathrm{m})$ & $1.07 \times 10^{-4}$ & $6.25 \times 10^{-4}$ & $2.90 \times 10^{-3}$ \\
$\mathrm{SE}(\mathrm{n})$ & $1.06 \times 10^{-3}$ & $6.18 \times 10^{-3}$ & $2.87 \times 10^{-2}$ \\
$\mathrm{SE}(\mathrm{r})$ & $3.34 \times 10^{-3}$ & $1.02 \times 10^{-2}$ & $4.87 \times 10^{-3}$ \\
LOD & 0.20 & 0.35 & 0.29 \\
LOQ & 0.66 & 1.16 & 0.96 \\
\hline
\end{tabular}

$\mathrm{m}$ : Slope of regression equation.

$\mathrm{n}$ : Intercept of regression equation.

r: Correlation coefficient.

SE (m): Standard error of slope.

SE (n): Standard error of intercept.

SE (r): Standard error of correlation coefficient.

LOD: Limit of detection $(\mu \mathrm{g} / \mathrm{mL})$.

LOQ: Limit of quantitation $(\mu \mathrm{g} / \mathrm{mL})$. 
Table 2. Recovery data obtained by applying PARAFAC model.

\begin{tabular}{llll}
\hline $\begin{array}{l}\text { Sample } \\
\text { number }\end{array}$ & $\begin{array}{l}\text { Test sample } \\
(\mu \mathrm{g} / \mathrm{mL})\end{array}$ & $\begin{array}{l}\text { Predicted } \\
\text { amount }(\mu \mathrm{g} / \mathrm{mL})\end{array}$ & Recovery $(\%)$ \\
\hline 1 & 0.8 & 0.81 & 101.7 \\
2 & 1.6 & 1.57 & 97.9 \\
3 & 4.8 & 4.91 & 102.3 \\
4 & 8.0 & 8.06 & 100.8 \\
5 & 11.2 & 11.18 & 99.9 \\
6 & 14.4 & 14.46 & 100.4 \\
Average & & & 100.5 \\
Standard deviation & & 1.53 \\
\multicolumn{2}{l}{ Relative standard deviation } \\
\hline
\end{tabular}

and its results showed that the method indicated a good capability to get precise and accurate results. In the assessment of the PARAFAC model's precision and accuracy, intra- and inter-day samples were prepared and analyzed. Their results for the quantitation of allura red in inter-day and intra-day samples containing colorant at three different concentration levels $(3.2,8.0$ and $12.8 \mu \mathrm{g} / \mathrm{mL})$ were shown in Table 3. In this test, the PARAFAC application gave a good agreement between actual and predicted concentrations.

In the method validation studies, the analysis of standard addition samples has a very important role to reveal the presence or absence of the effect of sample matrix on the quantitation of the related compound. For this aim, standard addition samples (at three concentration levels (low: $3.2 \mu \mathrm{g} / \mathrm{mL}$, medium: $8.0 \mu \mathrm{g} / \mathrm{mL}$ and high: $11.2 \mu \mathrm{g} / \mathrm{mL}$ ) with a constant amount of commercial energy drink product) were prepared as described in the section "2.3. Preparation of Calibration and Sample Solutions". PARAFAC analysis was subjected to standard addition samples and the added recovery results and relative standard deviations were computed and presented in Table 4. Although a signal for sample matrix interferences was observed in all profiles, the signal of sample's matrix was eliminated due to second-order advantage of PARAFAC model, then relative concentration profile was used for the quantitation. Thus, this application showed that PARAFAC implementation in the analysis of the food samples gave us more selective, precise Table 3. Analysis results of intra-day and inter-day studies by PARAFAC model.

\begin{tabular}{llllll}
\hline & $\begin{array}{l}\text { Added } \\
(\mu \mathrm{g} / \mathrm{mL})\end{array}$ & $\begin{array}{l}\text { Found } \\
(\mu \mathrm{g} / \mathrm{mL})\end{array}$ & Recovery $(\%)$ & RSD & RSE \\
\hline Intra-day & 3.2 & 3.3 & 101.9 & 0.21 & 1.85 \\
& 8.0 & 8.0 & 100.4 & 0.03 & 0.41 \\
& 12.8 & 12.7 & 99.4 & 0.12 & -0.60 \\
Inter-day & 3.2 & 3.3 & 101.9 & 0.14 & 1.88 \\
& 8.0 & 8.0 & 100.4 & 0.19 & 0.38 \\
& 12.8 & 12.7 & 99.1 & 0.09 & -0.95 \\
\hline
\end{tabular}

RSD: relative standard deviation.

RSE: relative standard error.
Table 4. Analysis results obtained from standard addition samples by PARAFAC model.

\begin{tabular}{llllll}
\hline Exp No. & & $\begin{array}{l}\text { Added } \\
(\mu \mathrm{g} / \mathrm{mL})\end{array}$ & $\begin{array}{l}\text { Found } \\
(\mu \mathrm{g} / \mathrm{mL})\end{array}$ & Recovery & RSD \\
\hline 1 & Sample + & 3.2 & 3.2 & 103.5 & 1.15 \\
2 & Sample + & 8.0 & 8.3 & 103.2 & 0.20 \\
3 & Sample + & 11.2 & 11.4 & 101.5 & 0.58 \\
\hline
\end{tabular}

RSD: Relative standard deviation.

and accurate results for recoveries and corresponding relative standard deviations for standard addition samples.

\section{3. $p K a$ determination of allura red}

The $\mathrm{pH}$ profile obtained from three-way PARAFAC analysis of the tensor of $\mathrm{pH}-\mathrm{UV}-\mathrm{Vis}-\mathrm{absor}-$ bance datasets was used for the estimation of acidity constant (or $\mathrm{pKa}$ ) of allura red. This $\mathrm{pH}$ profile for acid and base species of the analyzed colorant can be seen from Fig. 4e. In Fig. 4e, the red line and blue line correspond to acid and base species, respectively. The intersection of red (decreasing) and blue (increasing) lines in the $\mathrm{pH}$ profile were used to predict the $\mathrm{pKa}$ value of allura red in the analyzed energy drink. The numerical value of $\mathrm{pKa}$ for allura red was found to be 11.28 with a relative standard deviation of 1.197. This result was obtained from the average of three different measurements of the intersection point of acid and base lines in the related $\mathrm{pH}$ profile. In previously published studies, two different references on the colorant's acidity constant were reported $[26,50]$. When these results were compared with the PARAFAC model, good coincidence was observed.

\subsection{Quantitative analysis of energy drink product}

In order to show the applicability of the investigated three-way resolution method, the PARAFAC model was applied to the three-way array of $\mathrm{pH}$ UV-Vis-absorbance dataset and then the quantitation of allura red in commercial energy drink samples was performed. The relative concentration profile given in Fig. 4f was used for the calibration, prediction of validation samples and quantitative estimation of unknown concentration of allura red in commercial energy drink product.

The preparation of calibration samples was described in Section "Preparation of Calibration and Sample Solutions". In the preliminary studies, the concentration range of calibration samples was identified between $0.8-19.2 \mu \mathrm{g} / \mathrm{mL}$. A linear regression analysis was applied to the independent variables (actual concentration of allura red in 
calibration sample set) and dependent variables (estimated concentration levels of acidic component (red line)) in relative concentration profile of allura red's acid-base components illustrated in Fig. 4f. The statistical results obtained from the regression analysis and its related parameters were listed in Table 1. The computed linear regression function was used to estimate the amount of allura red in commercial energy drink samples. The obtained experimental results for the amount of allura red in analyzed commercial samples were presented in Table 5. In spite of the presence of interferences of sample matrix on the analysis of the related colorant, three-way resolution approach based on the PARAFAC application to pH-UV-Vis-absorbance dataset gave successful results for the analysis of a commercial energy product containing allura red and sample matrix without preliminary separation or extraction step.

\subsection{Classical UPLC analysis}

A new UPLC-PDA method was developed to determine the amount of allura red in the energy drink product. The UPLC analysis results for the related colorant were used to compare with those obtained by applying the PARAFAC tool to $\mathrm{pH}-\mathrm{UV}$ Vis-absorbance dataset.

In the development of the new classical UPLC method, Waters BEH C 18 (100 $\mathrm{mm} \times 2.1$ i.d., $1.7 \mu \mathrm{m})$ column was chosen as a stationary phase for the

Table 5. Quantitative analysis results of allura red in energy drink sample.

\begin{tabular}{llll}
\hline Exp. No & $\mathrm{mg} / 250 \mathrm{~mL}$ & & \\
\cline { 2 - 4 } & $\begin{array}{l}\text { PARAFAC } \\
\text { model }\end{array}$ & $\begin{array}{l}\text { Classical UV-VIS } \\
\text { spectroscopy }\end{array}$ & Classical UPLC \\
& 10.13 & 12.28 & 9.75 \\
1 & 10.26 & 12.29 & 10.09 \\
2 & 10.25 & 12.31 & 9.95 \\
3 & 10.27 & 12.19 & 9.91 \\
4 & 10.26 & 12.5 & 9.91 \\
5 & 9.92 & 12.23 & 9.94 \\
6 & 10.26 & 13.13 & 10.13 \\
7 & 10.05 & 12.32 & 10.48 \\
8 & 10.1 & 12.3 & 10.31 \\
9 & 10.23 & 12.29 & 10.06 \\
10 & 10.21 & 12.38 & 10.05 \\
Average & 0.14 & 0.27 & 0.22 \\
SD & 1.41 & 2.20 & 2.14 \\
RSD & $1.42(\mathrm{p}=0.19)$ & 22.76 & $\mathrm{t}$-crit: 2.26 \\
t-cal & & $\left(\mathrm{p}=2.9 \times 10^{-9}\right)$ & $(\alpha=0.05)$ \\
F-cal & $1.64(\mathrm{p}=0.24)$ & 3.23 & F-crit: 3.18 \\
& & $(\mathrm{p}=0.048)$ & $(\alpha=0.05)$ \\
\hline
\end{tabular}

SD: Standard deviation.

RDS: Relative standard deviation. chromatographic analysis of allura red in the analyzed energy drink. A mobile phase consisting of acetonitrile and $0.1 \mathrm{M} \mathrm{CH}_{3} \mathrm{COOH}$ containing $0.2 \%$ triethylamine $(18: 82, v / v)$ with the flow rate of $0.2 \mu \mathrm{L} /$ min and the sample injection volume of $1.0 \mu \mathrm{L}$ were found to be appropriate chromatographic conditions providing acceptable elution of the colorant and sample matrix in a commercial food product. Chromatographic detection was done at the wavelength of $240.0 \mathrm{~nm}$ and at room temperature. The chromatograms of the calibration set of allura red in the concentration range of $0.8-19.2 \mu \mathrm{g} / \mathrm{mL}$ were recorded. Fig. 5a shows the representative chromatogram of allura red standard. The retention time for the subjected colorant was reported to be 2.544 min as indicated in Fig. $5 \mathrm{a}$. In the calibration procedure, the linear regression equation and the related statistical results were given in Table 1 . In the newly developed UPLC application to samples, the recorded UPLC chromatogram was illustrated in Fig. 5b. From this figure, we can see a good separation between the colorant and sample matrix in marketed energy drink product. Quantitative analysis results of allura red in commercial samples were given in Table 5 . In the implementation of the newly developed UPLC method for commercial food samples, all the samples were prepared in water and filtered by cellulose nitrate filter with a pore size of $0.2 \mu \mathrm{m}$. The obtained UPLC results of allura red were used for the comparison of PARAFAC analysis.
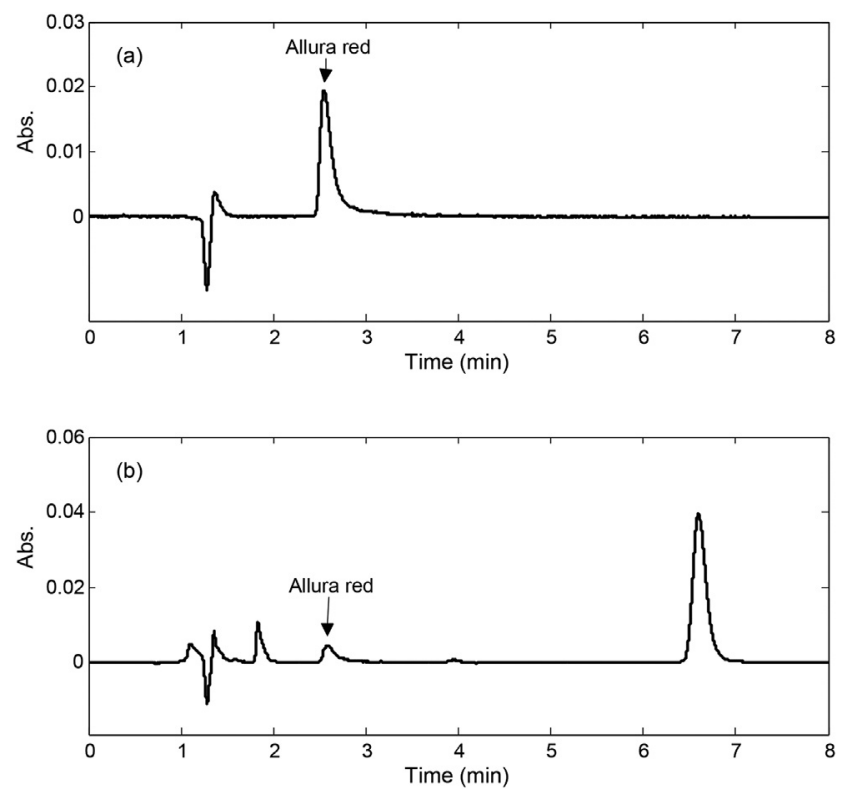

Fig. 5. UPLC chromatogram of (a) standard solution of allura red and (b) commercial energy drink sample. 


\subsection{Classical UV-Vis-spectroscopic analysis}

In order to observe the performance of the PARAFAC model for the resolution of complex food samples, a classical UV-Vis-spectroscopic method was used for the determination of allura red in energy drink samples. This classical UV-Vis spectroscopy is based on direct absorbance measurements at $495 \mathrm{~nm}$, which corresponds to the maximum wavelength for the absorption spectra of allura red at $\mathrm{pH}$ 10. Least square regression analysis and related statistical results for the method were listed in Table 1. Determination results of allura red obtained by the application of the classical spectroscopic approach to the commercial energy drink samples were indicated in Table 5 . As can be seen from this table, the assay result obtained by classical UV-Vis-spectroscopy showed a significant deviation from the results obtained by PARAFAC and UPLC methods. As a result, classical direct UV-Vis spectroscopic measurements were not suitable for the quantification of colorant due to the presence of sample's matrix in energy drink product.

\subsection{Statistical comparison of determination results}

In this paper, statistical tests ( $t$-test and F-test) were applied to compare the analysis results of allura red obtainedbytheapplicationofthreemethodstocommercial energydrinksamples.Inthesestatisticalprocesses,t-test wasused tocomparethemeansfortheanalysisresultsof PARAFAC-UPLC pair and classical UV-Vis spectroscopy-UPLCpair,whereasF-testwasusedtocomparethe variancesfortheanalysisresultsofPARAFAC-UPLCand classicalUV-Visspectroscopy-UPLC.

In the statistical tests, the critical values for $t(p=$ 0.05 with number of degree of freedom of 9 ) and $F(p$ $=0.05$ with degrees of freedom $n_{1}=9$ and $n_{2}=9$ ) found in tables are 2.26 and 3.18, respectively. At the 95\% confidence level, the difference between the experimental results for the commercial energy drink samples using PARAFAC and UPLC is not significant because $t$ - and F-calculated values were less than those of $\mathbf{t}$ - and F-critical values (See Table 5). However, a significant difference between classical UV-Vis spectroscopic and UPLC results was reported due to the effect of sample matrix on the analysis of allura red in commercial energy drink samples.

\section{Conclusions}

In this article, the application of three-way PARAFAC model to the $\mathrm{pH}-\mathrm{UV}-\mathrm{Vis}$ absorbance dataset gave successful results for the quantification of allura red and its pKa determination in the presence of interferences of sample's matrix in a commercial energy drink product. The proposed three-way analysis method provided us with the simultaneous determination of the colorant's amount and its pKa value using the deconvolution of the same dataset and without using a classical titration procedure. The simultaneous determination of these two characteristics would not be possible by classical UV-Vis spectroscopic and chromatographic approaches. This is an advantage of PARAFAC model over classical UVVis spectroscopy and UPLC methods. For a comparison of PARAFAC results, a newly developed UPLC method and a classical UV-Vis spectroscopic method were applied to the quantitation of allura red in samples. In spite of the complexity of food sample and the effect of the sample's matrix, we observed that the proposed PARAFAC application was faster, simpler, more accurate, precise and reliable than the classical methods, without requiring a sample preparation procedure. PARAFAC application required neither a sophisticated equipment, nor technical expertise, nor a sample preparation procedure.

\section{Acknowledgements}

In this study, analytical experiments and procedures were performed at the Chemometrics Laboratory of Faculty of Pharmacy, which was founded with the financial support of scientific research project number 10A3336001 of Ankara University. Authors also acknowledge the financial support from Ankara University through project 16L0237004.

\section{References}

[1] Riolo D, Piazza A, Cottini C, Serafini M, Lutero E, Cuoghi E, Gasparini L, Botturi D, Marino IG, Aliatis I, Bersani D, Lottici PP. Raman spectroscopy as a PAT for pharmaceutical blending: Advantages and disadvantages. J Pharmaceut Biomed 2018;149:329-34.

[2] Li Y, Shen Y, Yao C-1, Guo D-a. Quality assessment of herbal medicines based on chemical fingerprints combined with chemometrics approach: A review. J Pharmaceut Biomed 2020;185:113215.

[3] Tsai C-F, Kuo C-H, Shih DY-C. Determination of 20 synthetic dyes in chili powders and syrup-preserved fruits by liquid chromatography/tandem mass spectrometry. J Food Drug Anal 2015;23:453-62.

[4] Power AC, Chapman J, Chandra S, Cozzolino D. Ultravioletvisible spectroscopy for food quality analysis. Eval Tech Food Qual 2019:91-104.

[5] Arancibia JA, Damiani PC, Escandar GM, Ibañez GA, Olivieri $\mathrm{AC}$. A review on second- and third-order multivariate calibration applied to chromatographic data. J Chromatogr B 2012;910:22-30.

[6] Dinç E, Ertekin ZC, Ünal N. Three-way analysis of pH-UV absorbance dataset for the determination of paracetamol and 
its pKa value in presence of excipients. Spectrochim Acta A 2020:230.

[7] Dinç E, Ünal N, Ertekin ZC. Novel Three-Dimensional Resolution of a $\mathrm{pH}$ and Ultraviolet-Visible Absorption Spectral Dataset for the Determination of Desloratadine in a Pharmaceutical Product and Its Acid Dissociation Constant. Anal Lett 2020;53:1871-87.

[8] Harshman RA. Foundations of the PARAFAC procedure: Models and conditions for an "explanatory" multi-modal factor analysis. UCLA Working Papers Phonetics 1970;16: $1-84$.

[9] Tucker LR. Some mathematical notes on three-mode factor analysis. Psychometrika 1966;31:279-311.

[10] Wu HL, Shibukawa M, Oguma K. An alternating trilinear decomposition algorithm with application to calibration of HPLC-DAD for simultaneous determination of overlapped chlorinated aromatic hydrocarbons. J Chemom 1998;12:1-26.

[11] Sánchez E, Kowalski BR. Generalized Rank Annihilation Factor Analysis. Anal Chem 1986;58:496-9.

[12] Tauler R. Multivariate curve resolution applied to second order data. Chemometr Intell Lab 1995;30:133-46.

[13] Wold S, Geladi P, Esbensen K, Öhman J. Multi-way principal components-and PLS-analysis. J Chemom 1987;1:41-56.

[14] Zissis KD, Brereton RG, Dunkerley S, Escott REA. Two-way, unfolded three-way and three-mode partial least squares calibration of diode array HPLC chromatograms for the quantitation of low-level pharmaceutical impurities. Anal Chim Acta 1999;384:71-81.

[15] Rodrõguez-Cuesta MJ, Boqué R, Rius FX, Picón Zamora D, Martõnez Galera M, Garrido Frenich A. Determination of carbendazim, fuberidazole and thiabendazole by threedimensional excitation-emission matrix fluorescence and parallel factor analysis. Anal Chim Acta 2003;491:47-56.

[16] Mirzaei M, Khayat M, Saeidi A. Determination of paraaminobenzoic acid (PABA) in B-complex tablets using the Multivariate Curve Resolution-Alternating Least Squares (MCR-ALS) method. Scientia Iranica 2012;19:561-4.

[17] Soares PK, Bruns RE, Scarminio IS. Principal component and Tucker3 analyses of high performance liquid chromatography with diode-array detection fingerprints of crude extracts of Erythrina speciosa Andrews leaves. Anal Chim Acta 2012;736:36-44.

[18] Baum A, Hansen PW, Meyer AS, Mikkelsen JD. Simultaneous measurement of two enzyme activities using infrared spectroscopy: A comparative evaluation of PARAFAC, TUCKER and N-PLS modeling. Analytica Chimica Acta 2013;790:14-23.

[19] Bian X, Li S, Lin L, Tan X, Fan Q, Li M. High and low frequency unfolded partial least squares regression based on empirical mode decomposition for quantitative analysis of fuel oil samples. Anal Chim Acta 2016;925:16-22.

[20] Terra LR, Catrinck MN, Teófilo RF. MCR-ALS applied to the quantification of the 5-hydroxymethylfurfural using UV spectra: Study of catalytic process employing experimental design. Chemometr Intell Lab 2017;167:132-8.

[21] Dinç E, Büker E. Spectrochromatographic determination of dorzolamide hydrochloride and timolol maleate in an ophthalmic solution using three-way analysis methods. Talanta 2019;191:248-56.

[22] Rubio L, Sanllorente S, Sarabia LA, Ortiz MC. Determination of cochineal and erythrosine in cherries in syrup in the presence of quenching effect by means of excitation-emission fluorescence data and three-way PARAFAC decomposition. Talanta 2019;196:153-62.

[23] Insausti M, de Araújo Gomes A, Camiña JM, de Araújo $\mathrm{MCU}$, Band BSF. Fluorescent fingerprints of edible oils and biodiesel by means total synchronous fluorescence and Tucker3 modeling. Spectrochim Acta A 2017;175:185-90.

[24] Spagnuolo ML, Marini F, Sarabia LA, Ortiz MC. Migration test of Bisphenol A from polycarbonate cups using excitation-emission fluorescence data with parallel factor analysis. Talanta 2017;167:367-78.
[25] Avdeef A. pKa Determination. In: Avdeef A, editor. Absorption and Drug Development. 2nd ed. Hoboken, New Jersey, USA: John Wiley \& Sons, Inc.; 2012. p. 31-173.

[26] Glória MBA, Fernandes C. Synthetic Colorants. In: Nollet LML, Toldrá F, editors. Handbook of Food Analysis. vols. I. 3 ed. Boca Raton, FL, USA: CRC Press; 2015. p. 105-32.

[27] Zou T, He P, Yasen A, Li Z. Determination of seven synthetic dyes in animal feeds and meat by high performance liquid chromatography with diode array and tandem mass detectors. Food chemistry 2013;138:1742-8.

[28] Kirschbaum J, Krause C, Pfalzgraf S, Brückner H. Development and evaluation of an HPLC-DAD method for determination of synthetic food colorants. Chromatographia 2003; 57:S115-9.

[29] Yoshioka N, Ichihashi K. Determination of 40 synthetic food colors in drinks and candies by high-performance liquid chromatography using a short column with photodiode array detection. Talanta 2008;74:1408-13.

[30] Bonan S, Fedrizzi G, Menotta S, Elisabetta C. Simultaneous determination of synthetic dyes in foodstuffs and beverages by high-performance liquid chromatography coupled with diode-array detector. Dyes Pigm 2013;99:36-40.

[31] Shen Y, Zhang X, Prinyawiwatkul W, Xu Z. Simultaneous determination of red and yellow artificial food colourants and carotenoid pigments in food products. Food Chem 2014; 157:553-8.

[32] Bişgin AT, Uçan M. Narin I. Comparison of Column SolidPhase Extraction Procedures for Spectrophotometric Determination of E129 (Allura Red) in Foodstuff, Pharmaceutical, and Energy Drink Samples. J Aoac Int 2015;98:946-52.

[33] Elbanna K, Sarhan OM, Khider M, Elmogy M, Abulreesh $\mathrm{HH}$, Shaaban MR. Microbiological, histological, and biochemical evidence for the adverse effects of food azo dyes on rats. J Food Drug Anal 2017;25:667-80.

[34] Bişgin AT. Simultaneous preconcentration and determination of brilliant blue and sunset yellow in foodstuffs by solidphase extraction combined UV-vis spectrophotometry. J Aoac Int 2018;101:1850-6.

[35] Dinç E, Baydan E, Kanbur M, Onur F. Spectrophotometric multicomponent determination of sunset yellow, tartrazine and allura red in soft drink powder by double divisor-ratio spectra derivative, inverse least-squares and principal component regression methods. Talanta 2002;58:579-94.

[36] Berzas-Nevado JJ, Guiberteau-Cabanillas C, Contento-Salcedo AM, Martín-Villamuelas R. Spectrophotometric simultaneous determination of Amaranth, Ponceau 4R, Allura red and Red $2 \mathrm{G}$ by partial least squares and principal component regression multivariate calibration. Analytical Lett 1999; 32:1879-98.

[37] Bisgin AT. Simultaneous extraction and determination of Allura Red (E129) and brilliant blue FCF (E133) in foodstuffs by column solid-phase spectrophotometry. J Aoac Int 2019; 102:181-8.

[38] Kuo KL, Huang HY, Hsieh YZ. High-performance capillary electrophoretic analysis of synthetic food colorants. Chromatographia 1998;47:249-56.

[39] Pérez-Urquiza M, Beltrán JL. Determination of dyes in foodstuffs by capillary zone electrophoresis. J Chromatogr A 2000;898:271-5.

[40] Huang H-Y, Chiu C-W, Sue S-L, Cheng C-F. Analysis of food colorants by capillary electrophoresis with large-volume sample stacking. J Chromatogr A 2003;995:29-36.

[41] Kurtoglu M, Birbicer N, Kimyonsen U, Serin S. Determination of $\mathrm{pKa}$ values of some azo dyes in acetonitrile with perchloric acid. Dyes Pigm 1999;41:143-7.

[42] Ertan N. Synthesis of some hetarylazopyrazolone dyes and solvent effects on their absorption spectra. Dyes Pigm 1999; 44:41-8.

[43] Perez-Urquiza M, Prat MD, Beltran JL. Determination of sulphonated dyes in water by ion-interaction high-performance liquid chromatography. J Chromatogr A 2000;871: 227-34. 
[44] Perez-Urquiza M, Beltran JL. Determination of the dissociation constants of sulfonated azo dyes by capillary zone electrophoresis and spectrophotometry methods. J Chromatogr A 2001;917:331-6.

[45] El-Gahami MA, Mekky AEM, Saleh TS, Al-Bogami AS. Acidity constant and solvatochromic behavior of some pyrazolo 1,5-a pyrimidin-2-amine derivatives. Spectrochim Acta A 2014;129:209-18.

[46] Andersson CA, Bro R. The N-way toolbox for MATLAB. Chemometr Intell Lab 2000;52:1-4.

[47] Bro R. PARAFAC. Tutorial and applications. Chemometr Intell Lab 1997;38:149-71.
[48] Bro R. Exploratory study of sugar production using fluorescence spectroscopy and multi-way analysis. Chemometr Intell Lab 1999;46:133-47.

[49] Bro R, Kiers HA. A new efficient method for determining the number of components in PARAFAC models. J Chemom 2003;17:274-86.

[50] Pérez-Urquiza M, Beltrán J. Determination of the dissociation constants of sulfonated azo dyes by capillary zone electrophoresis and spectrophotometry methods. J Chromatogr A 2001;917:331-6. 